Cadernos Walter Benjamin 22

\title{
A REPRESENTAÇÃO ALEGÓRICA DA MODERNIDADE EM WALTER \\ BENJAMIN
}

Lucyane De Moraes

\section{RESUMO}

Em uma visão prospectiva ao contexto que originou a reflexão político-estética de Walter Benjamin, pode-se dizer que produções culturais tecnologicamente avançadas continuam a reproduzir os modelos industriais de comunicação vigentes à época, mantendo mais fortes as relações de dependência do sujeito com a produção fabril e com os sistemas privados de difusão, em conformidade com o apelo ideológico dos desempenhos políticos alcançados. Tal procedimento, visto como ideal de progresso técnico pode ser entendido como algo que resume, enquanto sintoma, uma situação histórica definida em termos hierarquizados, tendo no conceito de progresso a base ideológica que pressupõe o mundo como uma totalidade coerente. Em seu texto emblemático A obra de arte na era de sua reprodutibilidade técnica, o autor berlinense procurou contribuir criticamente para o entendimento das complexas questões que abarcam a ideia de continuum histórico, bem como os sistemas modelares fundamentais às relações hegemônicas que determinam as relações socioculturais marcadamente em termos institucionalizados, estabelecendo as bases estruturais que caracterizam e justificam ainda hoje certa ideia de Modernidade. Pari passu, pode-se também dizer que com a radicalização de ideias globais, a sociedade atual se beneficia com os avanços da técnica, mas perde em experiência humana.

Palavras-chave: Walter Benjamin, Cultura, Progresso, Técnica, Modernidade.

\section{THE ALLEGORICAL REPRESENTATION OF MODERNITY BY WALTER BENJAMIN}

\begin{abstract}
In a later view of Walter Benjamin's political-aesthetic thought, it can be said that technologically advanced cultural productions continue to reproduce the industrial models of communication in force at that time, expanding and keeping stronger relations of dependence between subject and industrial production, as in the private system of communication, according to an ideological ideal linked to political achievements. Seen as ideal of technical progress, such a procedure can be understood as something that, as a symptom, sums up a historical situation defined in hierarchical terms, based on an ideological concept of progress that assumes the world as a logical totality. In his emblematical essay The work of art in the age of mechanical reproduction, the author sought to give a critically contribute to the understanding of Doutora pela UFMG, com pesquisa em Estética e Filosofia da Arte e UERJ, com pesquisa em Ética e

Filosofia Política. Brasileira, residente no Rio de Janeiro. E-mail: cinetoscopio@yahoo.com.br
\end{abstract}


intricate issues that cover the idea of a historical continuum, as well as the model systems fundamental to the hegemonic relations that determine the sociocultural relations notably in an institutional way, firming the structural bases which distinguish and justify even today a certain idea of Modernity. Pari passu, one can also say that, according to radical global ideas, contemporary society benefits from advances in technique, but at the same time loses human experience.

Keywords: Walter Benjamin, Culture, Progress, Technique, Modernity.

\section{Introdução}

Como se sabe, a história social da primeira metade do século XX registra um quadro de violência até então inédito, consequência, entre outras, da eclosão de duas guerras mundiais. Com a derrocada de uma ideia de civilização calcada na reflexão crítica e no exercício do filosofar, a sociedade em sua constituição moderna passou a ser caracterizada pelo culto à ciência tecnológica, consolidado como cultura hegemônica, tendo como projeto a representação política do consumo de massas possibilitado pelo uso absoluto de máquinas e dispositivos industriais. Sob essa ótica, a técnica é apresentada como palavra-chave para designar o progresso material, sendo esse o contexto em que Walter Benjamin produz a totalidade de sua obra.

Quando Marx empreendeu a análise do modo de produção capitalista, este ainda estava nos primórdios. Marx conduziu sua investigação de tal modo que ele adquiriu o valor de um prognóstico. Partindo das relações fundamentais do modo capitalista, descreveu-as de forma a tornar possível antever o que o futuro nos reservaria. $O$ capitalismo tendia a intensificar cada vez mais a exploração do proletariado e, por fim, criar as condições necessárias à sua abolição. Como as mudanças na superestrutura ocorrem muito mais lentamente do que aquelas na infraestrutura foi preciso mais de meio século para que as mudanças ocorridas nas condições de produção repercutissem em diversos terrenos da cultura. Só hoje é possível observar como isso aconteceu. Podemos fazer alguns prognósticos a partir dessas observações [...] A dialética dessas condições não é menos perceptível na superestrutura que na economia (BENJAMIN, 1969, 9).

Sabe-se que a obra de Benjamin, composta sempre na forma ensaística, consiste de prefácios, palestras, roteiros radiofônicos, resenhas de livros, relatos de viagens, anotações aforísticas, rascunhos inconclusos, folhetins de temas culturais e sociais, de bibliografias a temas arquitetônicos. Sendo o corpus de seus escritos voltado para o entendimento das questões éticas subjacentes às formas da Doutora pela UFMG, com pesquisa em Estética e Filosofia da Arte e UERJ, com pesquisa em Ética e Filosofia Política. Brasileira, residente no Rio de Janeiro. E-mail: cinetoscopio@yahoo.com.br 
racionalidade, aponta, sempre sob um enfoque interdisciplinar, para a experiência vivida do choque (Chockerlebnis) que serviu de instrumento fundamental para 0 entendimento da arte, da cultura e das sociedades modernas, interpretando as novas realidades surgidas no século XX, valorizando a percepção da experiência (Erfahrung). Ou seja, um pensar de sentido particular desenvolvido enquanto uma interpretação não afeita meramente à lógica conceitual, mas próprio de um ideal materialista: "O marxismo, que ele [Benjamin] assimilou a seu modo e em termos extremamente peculiares, combinou-se com a consciência prévia, que ele tinha, de que era preciso alimentar a esperança de que um mundo bem melhor podia ser criado" (KONDER, 1988, 11).

\section{I}

A obra de Benjamin incide na forma de uma escrita que se constitui enquanto um jogo enigmático e não demanda necessariamente resposta conceitual. Como lembrado por Adorno, sua forma de expressão se dá por meio da exposição (Darstellung) - a linguagem. Conforme o próprio Benjamin "a ideia é algo de linguístico, é o elemento simbólico presente na essência da palavra" (BENJAMIN, 1984, 58-59). Pensada, então, como experiência vivida do choque a filosofia de Benjamin é constituída por paradoxos, buscando superar o caráter meramente conceitual, aproximando-se do indizível. Segundo Leandro Konder, "para Benjamin o conceito é apenas o mediador entre o fenômeno singular e a ideia universal". O filósofo petropolitano explica, também, que para Benjamin:

O conceito representa a ideia, tornando-a viva, e ao mesmo tempo redime os fenômenos, salvando-os da dispersão, evitando que eles se percam no mundo empírico. Só as ideias são efetivamente universais. Os fenômenos precisam das ideias para poder se agrupar significativamente, para não se dissolverem sem deixar traço; porém, eles não têm, nem podem ter acesso direto à universalidade: dependem do trabalho dos conceitos para chegarem lá. As ideias, por sua vez, necessitam da vitalidade que os fenômenos singulares Ihes trazem. «Elas permanecem escuras, até que os fenômenos as reconheçam e circundem». Benjamin recorre a uma analogia para explicar seu ponto de vista: «As ideias se relacionam com as coisas como as constelações com as estrelas». O conceito não pode ser tão universal como supunha Hegel, porque - sustenta Benjamin - ele precisa permanecer ligado à singularidade dos fenômenos, à realidade empírica. De acordo com a analogia citada acima, o conceito não pode se afastar das estrelas individualmente consideradas. A universalidade das ideias depende da

Doutora pela UFMG, com pesquisa em Estética e Filosofia da Arte e UERJ, com pesquisa em Ética e Filosofia Política. Brasileira, residente no Rio de Janeiro. E-mail: cinetoscopio@yahoo.com.br 
autonomia delas em relação aos fenômenos. Para serem plenamente universais, para serem 'essenciais', as ideias precisam valer por si mesmas, precisam ser completamente independentes, precisam ser independentes até mesmo umas das outras. "Cada ideia é um sol e se relaciona com outras ideias tal como o sol se relaciona com outros sóis». As ideias, então, são autárquicas: são mônadas (KONDER, 1988, 28-29).

Para Benjamin "a ideia é mônada", significando dizer que "cada ideia contém a imagem do mundo". Sobre isso, o filósofo explica: "a representação da ideia impõe como tarefa nada menos que a descrição dessa imagem abreviada do mundo" (BENJAMIN, 1984, 70). Ainda, de acordo com Konder, "Benjamin era um filósofo voltado para o passado, empenhado na recuperação de energias libertadoras antigas, convencido de que a solução do enigma do nosso porvir depende - de algum modo da compreensão do nosso ponto de partida" (KONDER, 1988, 33). Em sendo assim, pode-se dizer que com sua obra Benjamin empreende esforços na configuração política de "imagens históricas", no movimento intermitente entre "sonho e despertar da consciência", inaugurando uma nova forma de estética fundada na filosofia da história, o que o faz tornar-se um dos principais interlocutores da vanguarda artística por meio de uma espécie de princípio des-organizador, objetivando dar um novo sentido (histórico-estético) a uma obra de arte, ampliando seu sentido para discursos mais próprios a uma ideia de Modernidade.

Há um quadro de Klee que se intitula Angelus novus. Representa um anjo que parece querer afastar-se de algo que ele encara fixamente. Seus olhos escancarados, sua boca dilatada, suas asas abertas. Tal deve ser o aspecto do anjo da história. Seu rosto está dirigido para o passado. Onde nós vemos uma cadeia de acontecimentos, ele vê uma catástrofe única, que acumula incansavelmente ruína sobre ruína e as joga aos seus pés. Ele gostaria de deter-se para despertar os mortos e reunir os vencidos, mas uma tempestade sopra do paraíso e prende-se em suas asas com tanta força que ele não pode mais fechá-las. Essa tempestade o impele irresistivelmente para o futuro, ao qual ele dá as costas, enquanto o amontoado de ruínas cresce até o céu. Essa tempestade é o que chamamos progresso (BENJAMIN, 1985, 226).

Em outras palavras, pode-se dizer que para Benjamin o desafio de pensar historicamente o passado consiste na tentativa de não se debruçar sobre aquilo que já se encontra ultrapassado no âmbito da tradição, mas de refletir sobre o que "não é conhecido" e que encerra o paradoxo da experiência humana. Com isto, lembra o filósofo que articular historicamente o passado não significa conhecê-lo como ele de fato foi. Vale, ainda, ressaltar que apesar de sua diversidade temática, o autor Doutora pela UFMG, com pesquisa em Estética e Filosofia da Arte e UERJ, com pesquisa em Ética e Filosofia Política. Brasileira, residente no Rio de Janeiro. E-mail: cinetoscopio@yahoo.com.br 
possibilita ao leitor sua própria possibilidade de reflexão singular, bem ao modo daquilo que o filósofo preconiza em termos de experiência. Com isso, ao acionar aquilo que a consciência desperta por meio da memória, entende que é possível conectar passado e presente em sentido crítico. Pautada por considerações sociais, entre as intenções revolucionárias do proletariado e reações conservadoras do mundo do capital, as referências da obra de Benjamin abarcam a estética, a ciência, a história e a psicologia, sempre com ênfase no sujeito, mas não pretendendo nunca apresentá-lo enquanto algo acabado.

\section{II}

Sabe-se que o maior adversário de Benjamin "era a grande burguesia alemã que a seu ver era a maior responsável pela terrível crise inflacionária dos anos vinte". De acordo com Konder: "antes de ser um revolucionário, Benjamin era um rebelde apaixonadamente antiburguês, que desprezava a apologia liberal da «moderação» e da "sobriedade»". Aliás, para o filósofo berlinense: "o sóbrio, que não tem nenhuma idiossincrasia, vive sem conhecer convicções" (BENJAMIN apud KONDER, 1988, 4046). Contemporâneo de ambos os pensadores, Ernest Bloch, que conhece Benjamin no final da década de 1910, ao reencontrá-lo em Berlim no ano de 1923, recomenda ao filósofo berlinense a leitura de História e consciência de classe. Sabe-se que foi grande o impacto da leitura do jovem Lukács na vida e obra de Benjamin, sobretudo, pelas análises do filósofo húngaro no que respeita ao fenômeno da reificação. Sobre isso, assim relata Konder:

Através de Lukács, o pensamento de Marx lhe parecia proporcionar instrumentos notavelmente fecundos para a crítica do presente, para a desmitificação implacável das construções ideológicas geradoras de confusão e conformismo. Benjamin descobriu, então, em Marx, uma riqueza maior do que aquela que antes havia podido enxergar; passou a se interessar apaixonadamente pelas formas da distorção que os mecanismos do mercado capitalista acarretavam na consciência dos homens. Passou a encarar, como desdobramento natural das suas novas posições, a atuação política no PC. Escreveu a Scholem: «provavelmente intensificarei meus contatos com a política marxista e ingressarei no partido» [maio de 1925] (KONDER, 1988, 33).

Pode-se dizer, então, que a noção de fantasmagoria de Benjamin desenvolvida, por exemplo, em seu projeto das Passagens (1927-1940), situa-se na teoria do Doutora pela UFMG, com pesquisa em Estética e Filosofia da Arte e UERJ, com pesquisa em Ética e Filosofia Política. Brasileira, residente no Rio de Janeiro. E-mail: cinetoscopio@yahoo.com.br 
fetichismo da mercadoria, de Marx, bem como no alargamento do conceito de reificação, de Lukács. E, em sendo assim, o pensador berlinense, ao promover uma crítica sobre a apologia do formalismo e racionalismo na Modernidade, irá contribuir efetivamente para o desenvolvimento da reflexão em um sentido histórico-materialista em consonância com o pensamento marxista. Sob esta ótica, entende-se que a centralidade das formulações de Benjamin é um contributo das teorias desenvolvidas por Marx e Lukács, elaborada como uma crítica rigorosa ao pensamento identificador e geral. Partindo dessa questão, Benjamin promove um entendimento do conceito de reificação, baseando-o de forma objetiva nas relações sociais, agregando ao conceito uma totalidade de elementos filosóficos na busca de esclarecer como tal procedimento intensifica as forças produtivas ao mesmo tempo em que silencia as forças de resistência subjetivas.

A ideia de que o desenvolvimento das forças produtivas engendra uma onda, que afinal, de um modo ou de outro, sempre nos empurra para frente era, para Benjamin, uma ideia tendenciosa, enganadora: ela nos leva a ver os problemas sociais de um ponto de vista que já não é o das pessoas dos trabalhadores, mas o do próprio trabalho. Ao enfatizar os progressos na dominação da natureza, ela tende a obscurecer os retrocessos que se dão na sociedade (KONDER, 1988, 7).

Sendo assim, o conceito de reificação, enquanto processo de alienação (Entäusserung) das relações de produção no capitalismo, pressupõe o predomínio do objeto sobre o sujeito, invertendo o sentido relacional de ambos os conceitos conforme estabelecido em termos originais. Sua análise sobre o fenômeno do fetichismo, elaborada de maneira crítico-alegórica é vista como uma nova forma de "representação" do mundo moderno do capital, indicada, por exemplo, nos poemas de Baudelaire, possibilitando desmitificar a realidade totalizante formal imposta pela fantasmagoria da tríade forma-mercadoria-dinheiro na Modernidade. Nota-se que o interesse de Benjamin pela obra de Baudelaire diz respeito à perspectiva alegórica, que, de acordo com o pensador berlinense, era capaz de "demolir a fachada harmoniosa do mundo que a cercava" (BENJAMIN, 2009, 374). Sob esse prisma a "representação" alegórica da Modernidade é, para Benjamin, uma maneira de romper com todos os parâmetros de uma totalidade harmônica fantasmagórica burguesa: "a alegoria, precisamente em seu furor destrutivo, visa a aniquilação da aparência 
baseada na 'ordem estabelecida' seja da arte, seja da vida - a aparência de uma totalidade ou de um mundo orgânico que transfigura essa ordem, para torná-la suportável" (BENJAMIN, 2009, 377). Pode-se dizer que o posicionamento de Benjamin à problemática da reificação e fetichismo da mercadoria não é outro senão de ordem estético-político:

A chave da forma alegórica em Baudelaire é solidária da significação específica que a mercadoria adquire devido a seu preço. Ao aviltamento das coisas por meio do seu significado, que é característico da alegoria do século $\mathrm{XVII}$, corresponde o aviltamento singular das coisas por meio do seu preço, enquanto mercadoria (BENJAMIN, 2009, 62).

Tal ideia pressupõe a necessidade de uma reorientação dos objetivos da produção e consumo de bens materiais e imateriais, tendo como fito a transformação de tais relações enquanto totalidade, objetivada, então, como tentativa de superação do quadro existente. Por oportuno, vale lembrar uma menção a Benjamin feita ainda por Konder, que de forma simbólica relata, em referência à expressão artística funcional, uma famosa passagem da vida do filósofo berlinense:

O socialista utópico Fourier, que Benjamin lia com imenso gosto, inventara a palavra "falanstério" para designar a comunidade ideal, onde os seres humanos aprenderiam a ser solidários. Benjamin, para caracterizar a sociedade burguesa do seu tempo como centro de fabricação de filisteus, inventou a palavra "filistério". Viajando pela Itália e pela França, ele pode constatar os efeitos devastadores do funcionamento pragmático do "filistério" no plano da expressão artística. Em visita à catedral de Marseille, espantado com a feiura do prédio, mas reconhecendo a eficiência do seu funcionamento, ele o comparou, ironicamente, a uma estação ferroviária: "é a estação ferroviária da religião. Todos os dias, na hora da missa, trens com vagão-leito partem dali para a eternidade" (KONDER, 1988, 41).

Este ideal de Modernidade se encontra amparado por uma imagem idealizada de progresso e se aplica à medida a um suposto indivíduo coisificado (dinghafte), totalmente sublimado, não histórico e sem transcendência, sendo este o modo no qual a noção de racionalidade instrumentalizada encontra a sua mais eficiente forma de aplicação. Sobre isso, Benjamin afirma que:

A crença no progresso, em sua infinita perfectibilidade - uma tarefa infinita da moral -, e a representação do eterno retorno são complementares. São as antinomias indissolúveis a partir das quais deve ser desenvolvido o conceito dialético do tempo histórico. Diante disso, a ideia do eterno retorno aparece como o 'racionalismo raso', que a crença no progresso tem a má fama de representar, sendo que esta crença pertence à maneira de pensar mítica tanto quanto a representação do eterno retorno (BENJAMIN, 2009, 159).

Doutora pela UFMG, com pesquisa em Estética e Filosofia da Arte e UERJ, com pesquisa em Ética e Filosofia Política. Brasileira, residente no Rio de Janeiro. E-mail: cinetoscopio@yahoo.com.br 
Acrescenta-se, ainda, que tal ideia de progresso pode ser entendida como algo que resume, enquanto sintoma, uma situação histórica definida em termos hierarquizados, tendo no conceito de progresso a base ideológica que pressupõe 0 mundo como uma totalidade coerente. Sob esse enfoque, reporta-se também à impotência que tal entendimento hegemônico impõe aos indivíduos, como um dos efeitos daquilo que Marx denominou "fetiche da mercadoria". Não por outra razão, a intenção de Benjamin é dar continuidade à investigação sobre o caráter de fetichismo da mercadoria, por meio do despertar da consciência, denunciando o sono profundo (inconsciente) do mundo burguês. "A verdadeira libertação de uma época possui a estrutura do despertar, também pelo fato de ser inteiramente regida pela astúcia. Com astúcia, e não sem ela, libertamo-nos do reino do sonho" (BENJAMIN, 2009, 209).

III

Em seu Exposé, de 1935, o autor berlinense afiança que: "à forma do novo meio de produção, que no início ainda é dominada por aquela do antigo (Marx), corresponde na consciência coletiva imagens nas quais se interpenetram o novo e o antigo". Sobre isso, o próprio filósofo esclarece:

Essas imagens são imagens do desejo e nelas o coletivo procura tanto superar quanto transfigurar as imperfeições do produto social, bem como as deficiências da ordem social de produção. Ao lado disso, nestas imagens de desejo vem à tona a vontade expressa de distanciar-se daquilo que se tornou antiquado - isso significa, do passado mais recente. Estas tendências remetem a fantasia imagética, impulsionada pelo novo, de volta ao passado mais remoto. No sonho, em que diante dos olhos de cada época surge em imagem a época seguinte, esta aparece associada a elementos da história primeva, ou seja, de uma sociedade sem classes (BENJAMIN, 2009, 41).

Com isso, Benjamin parece se referir ao indivíduo refém, por assim dizer, de uma temporalidade mítica, imerso em uma espécie de amanhã-eterno que o aliena em termos de consciência histórica, referindo-se à condição do indivíduo entregue à sua própria sorte na sociedade do eternamente-o-mesmo das trocas universais. No entanto, tal referência adquire sentido figurado, uma vez que as relações mercantis vêm há muito assumindo, como segunda natureza, formas alternativas àquelas tradicionalmente circunscritas nos processos de troca, incorporando outros sentidos para a mercadoria que vão muito além daqueles que decorrem da mera posse física

Doutora pela UFMG, com pesquisa em Estética e Filosofia da Arte e UERJ, com pesquisa em Ética e Filosofia Política. Brasileira, residente no Rio de Janeiro. E-mail: cinetoscopio@yahoo.com.br 
dos objetos. É sob esta ótica que o filósofo berlinense alude ao fato de que "o retorno do sempre igual manifesta-se de maneira patente na produção de massa" (BENJAMIN, 2009, 376). Ao recorrer ao conceito de fetichismo da mercadoria, considerado Leitmotiv de suas Passagens, Benjamin endossa a tese baudelairiana de que, no mundo moderno do capital, o mesmo - continuado em processo de repetição - embora se apresente como novidade, revela uma experiência esvaziada de conteúdo, determinando uma realidade fictícia.

Criada com base no desejo consumidor e na exploração da multidão, a dinâmica da produção da mercadoria consiste em fabricar diferentes produtos que deem a sensação de que o sujeito-consumidor esteja ilusoriamente adquirindo sempre algo novo. E, assim, o novo que aparece é tão-somente o mesmo (das Immer-gleiche) que domina a produção material da sociedade: "o novo não é feito de outra matéria que não dessa fantasmagoria do sempre-igual" (BENJAMIN, 2009, 62). É deste modo que o filósofo berlinense explica a dialética da produção de mercadorias no apogeu do capitalismo: "a novidade do produto adquire - como estímulo da demanda - uma importância até então desconhecida" (BENJAMIN, 2009, 376).

Por tudo isso, alude Benjamin que o enfraquecimento da subjetividade humana, por meio do nivelamento com as relações de troca, se coaduna com uma ideia de Modernidade imposta em sentido macro, assinalando os consequentes impactos causados por tal fenômeno. Consequentemente, pode-se dizer que o que resulta disso é fator de aniquilamento da subjetividade e, portanto, um traço de violência que possibilita diferentes modos de comprometimento da memória, traduzido pela falência da capacidade imaginativa do indivíduo ou, como diria Benjamin em sentido específico, pela perda da capacidade de narrar, entre outras. Assim é que o pensador berlinense, em seu ensaio O narrador (1936), revela que "a arte de narrar está definhando porque a sabedoria - o lado épico da verdade - está em extinção" (BENJAMIN, 1987, 200201). E, continua ainda:

Contar história sempre foi a arte de contar de novo, e elas se perdem quando as histórias não são mais conservadas. Ela se perde porque ninguém mais fia ou tece enquanto ouve histórias. Quanto mais o ouvinte se esquece de si mesmo, mais profundamente se agrava nele o que é ouvido. Quando o ritmo do trabalho se apodera dele, ele escuta as histórias de tal maneira que adquire espontaneamente o dom de narrá-las. Assim se teceu a rede em que está

Doutora pela UFMG, com pesquisa em Estética e Filosofia da Arte e UERJ, com pesquisa em Ética e Filosofia Política. Brasileira, residente no Rio de Janeiro. E-mail: cinetoscopio@yahoo.com.br 
guardado o dom narrativo. E assim essa rede se desfaz hoje por todos os lados, depois de ter sido tecida, há milênios, em torno das mais antigas formas de trabalho manual (BENJAMIN, 1987, 205).

Aludida por Benjamin como "forma artesanal de comunicação", a capacidade de narrar "fala" sobre a experiência vivida daquele que a pronuncia, em termos cognitivos, sendo possível estabelecer de forma complementar uma analogia com procedimentos mais afeitos ao modus operandi da arte, determinados, por sua vez, como forma artesanal de expressão. "Assim se imprime na narrativa a marca do narrador, como a mão do oleiro na argila do vaso" (BENJAMIN, 1987, 205).

\section{IV}

Sabe-se que a noção de Modernidade pode ser definida pelo jogo de forças e tensão intermitente entre lembrança e esquecimento, pela caducidade e pelo combate em pretender conservar os instantes do tempo fugidio. Com isso, a urdida aspiração de Modernidade, ao inibir no sujeito a capacidade potencial de acesso e uso da memória, passa a subverter a relação de pertencimento, vivência e experiência entre ele e a realidade social. Em um sentido mais amplo pode-se dizer que a relativização do significado e a perda da memória dos indivíduos propiciam, também, um aniquilamento da vontade oral de narrar - e até mesmo de historiar - como consequência de empobrecimento da experiência social, de ordem coletiva.

Em outras palavras, a Modernidade, definida nesses termos, resulta em sua própria negação na medida em que se opondo a algo estabelecido, em sendo aceita como padrão se torna, sem qualquer rastro de referência, outro algo estabelecido, gerando uma série de contradições internas que acaba por afirmar sua própria condição obsolescente. Não por outro motivo Benjamin evoca a sentença de Baudelaire, de que "toda Modernidade é digna de um dia se tornar antiguidade", ou ainda, que a "Modernidade designa uma época e designa ao mesmo tempo a força em relação a essa época, que a aproxima da Antiguidade" (BENJAMIN, 2015, 83). É, por exemplo, como ideal autônomo oposto à tradição que o filósofo berlinense entende que a noção baudelairiana de modernité se torna objeto de valor inestimável para o mundo industrial. Marcada pela fugacidade dos fenômenos, a Modernidade não é uma 
peculiaridade de certa época e, sim, um momento específico comum a todas as épocas, cada qual fundado em sua própria especificidade momentânea. Equivale dizer que, na efemeridade do moderno, o novo torna-se antigo e o moderno se faz superado por outro novo. Sobre isso, Benjamin afirma que: "a Modernidade manteve-se menos igual a si mesma do que qualquer outra coisa e a Antiguidade que nela estaria contida representa de fato a imagem do antiquado" (BENJAMIN, 2015, 91). Deste modo, como imagem do progresso, tal ideal de Modernidade se aplica à medida a um sujeito idealizado: "o herói é o verdadeiro sujeito dessa Modernidade". É com essa afirmação que o filósofo berlinense - em consonância om Balzac e Baudelaire (que se opõem ao Romantismo) - alude ao fato de que "para viver a Modernidade é preciso uma formação heroica". E escreve:

O herói é tão forte, tão engenhoso, tão harmonioso, tão bem-construído como os veleiros. Mas é em vão que o alto-mar o chama, porque a sua vida foi posta sob o signo da má estrela. A Modernidade é seu destino fatal. Nela, o herói não está previsto, ela não sabe o que fazer com esse tipo de homem. Prendeo para sempre a um porto seguro; entrega-o a uma eterna ociosidade (BENJAMIN, 2015, 97).

Desprovido de qualquer sentido de tradição, o indivíduo se torna então aquele, por excelência, constituído à imagem das próprias relações de troca, justificando o contexto amnésico de sua ofuscação. De acordo com Benjamin "os obstáculos que a Modernidade opõe ao élan produtivo natural do indivíduo são desproporcionais às suas forças" (BENJAMIN, 2015, 77). É deste modo que tal noção de Modernidade se apresenta enquanto algo a serviço de interesses que se aferram em atribuir à tradição um sentido de inconsciência temporal. Assim, o pensador berlinense entende que tal noção de Modernidade "desproporcional às forças humanas" se torna objeto de valor inestimável para um mundo metamorfoseado em indústria, constituído por um estado de amnésia permanente, implicitamente não histórico, eivado de ideal estéril de novidade. De tal modo, como imagem do "progresso", tal ideal de Modernidade se aplica à medida a um suposto sujeito "totalmente sublimado" e "atemporal".

A Modernidade, portanto, não é uma etapa histórica destinada à superação do legado da tradição e de tudo aquilo que a delimita historicamente. Então, é enquanto memória produtiva que tradição e consciência histórica guardam em si o mesmo sentido, sendo mais consequente pensar a ideia de moderno como um conceito que Doutora pela UFMG, com pesquisa em Estética e Filosofia da Arte e UERJ, com pesquisa em Ética e

Filosofia Política. Brasileira, residente no Rio de Janeiro. E-mail: cinetoscopio@yahoo.com.br 
se completa na experiência da tradição, o que justifica dizer que o termo Modernidade guarda em si uma categoria qualitativa, não somente cronológica, para além daquilo que o mero senso comum atribui ao termo. De acordo com Benjamin "há certa constelação na qual se encontra também no homem, a grandeza e o desprendimento. É nela que rege a existência de Baudelaire, que a decifrou e the deu o nome de Modernidade" (BENJAMIN, 1985, 97). De mais a mais, no que tange às considerações de Baudelaire, cabe citar o poeta francês que, em seu artigo O pintor da vida moderna, proferiu:

A Modernidade é o transitório, o efêmero, o contingente, é a metade da arte, sendo a outra metade o eterno e o imutável. Houve uma modernidade para cada pintor antigo; a maioria dos belos quadros que nos restam dos tempos anteriores está vestida com os trajes de sua época. Eles são perfeitamente harmônicos, pois a roupa, o penteado e mesmo o gesto, o olhar e o sorriso (cada época possui seu porte, seu olhar e seu sorriso), formam um tudo de uma completa vitalidade. Esse elemento, transitório, fugidio, cujas metamorfoses são frequentes, vocês não têm o direito de desprezar ou dispensar (BAUDELAIRE, 1996, 25).

Constituída como reflexo de uma memória vivida contra o esquecimento, Modernidade é, então, tudo aquilo que se estabelece como legado da tradição, demarcada em seu interior por processos estabelecidos historicamente. Sobre isso, também elucida Henri Bergson: "basta ter-se convencido de uma vez por todas de que a realidade é mudança, de que a mudança é indivisível e de que, numa mudança indivisível, o passado se consubstancia com o presente" (BERGSON, 1999, 179). Considerar, portanto, a antinomia entre tradição e Modernidade é per se uma herança da racionalidade instrumental, reminiscente das formas de dominação, o que vale evocar o aforismo do filósofo, poeta, ensaísta e romancista espanhol George Santayana de que "quem não conhece o passado está condenado a revivê-lo" (SANTAYANA, 1920, 284).

Assim é que para Benjamin "a Antiguidade e a Modernidade se interpenetram" (BENJAMIN, 2015, 89). Isso significa dizer, em outras palavras, que "a relação com a Antiguidade é uma das mais significativas entre todas as estabelecidas pela Modernidade" (BENJAMIN, 2015, 83). Para se entender tal relação, basta lembrar o fato de que para Benjamin a Modernidade designa um dado momento histórico, uma época e "designa ao mesmo tempo a força de ação nessa época, que a aproxima da 
Antiguidade" (BENJAMIN, 2015, 83), resumindo assim uma relação de complementariedade que aproxima ambas as esferas. No entanto, aquilo que as aproxima pode ser entendido também como o que as separa. Neste sentido, chama a atenção o argumento de Benjamin, de que "o moderno opõe-se ao antigo, o novo ao sempre-igual" (BENJAMIN, 2015, 179). Importante ressaltar, também, o que lembra Benjamin ao referir-se que "em Baudelaire, o «moderno» não assenta única e principalmente na sensibilidade. Nele exprime-se uma espontaneidade suprema; a Modernidade em Baudelaire é uma conquista, tem uma armadura" (BENJAMIN, 2015, 158). E, em sendo assim, parodiando o filósofo berlinense, "a alegoria é a armadura da Modernidade" (BENJAMIN, 2015, 179). Soma-se a isso, a célebre passagem em que Benjamin, aludindo claramente à dimensão subjetiva humana, assinala a condição de sentido cultural somente dada ao homem de reprodução das ações cotidianas sempre de uma forma diferente, expressão máxima da condição criativa que caracteriza o humano.

\section{V}

Como associação, pode-se atribuir a Benjamin uma também ideia alegórica de reprodução dos meios técnicos na arte, de acordo com seu conhecido ensaio $A$ obra de arte na era de sua reprodutibilidade técnica, onde o filósofo abre espaço para uma reflexão prospectiva acerca da possibilidade de se incorporar os avanços tecnológicos ao processo de "produção de uma arte mecânica emancipada da arte a serviço das massas". Por outro lado, em sentido dialético tal ideia também se coaduna perfeitamente com a concepção acrítica do uso da técnica nas sociedades do capital, como, aliás, bem diagnosticou Benjamin com o seu conceito de aura, originalmente voltado para as artes plásticas, alarga sua acepção para esse âmbito artístico. Ao referir-se, por exemplo, ao aspecto da reprodução técnica da arte, via difusão mercadológica, o filósofo alude à perda do sentido de realidade da obra pela sua reprodutibilidade técnica, resultando em uma espécie de quebra do encanto único da obra, ou em outras palavras, à perda de sua aura artística.

Como se sabe, o conceito de unicidade, bem como a análise do seu declínio na 
Modernidade se encontra no centro da teoria estética benjaminiana desde fins da década de 1920, momento em que o autor berlinense inicia o seu projeto das Passagens. Nesse período Benjamin empreendia esforços na tentativa de compreender os novos modos de produção artística. Interessante notar como Benjamin, ao dimensionar o hic et nunc artístico, atribui a essa categoria um sentido de espaço e tempo, ou seja, o lócus específico da reprodução artística relacionado ao momento único de sua ocorrência, significando dizer que a arte ao ser reproduzida artificialmente pela tecnologia perde automaticamente tanto o seu hic quanto o seu nunc, ou seja, o seu "aqui" e o seu "agora" que a determina espacial-temporalmente, retirando dela a sua unicidade "aurática" autêntica. Não é por outra razão que Benjamin define o conceito de aura como "aparição única de algo distante por mais próximo que esteja" (BENJAMIN, 2012, 14), dimensionando o seu sentido no âmbito essencialmente espacial e temporal em termos imagéticos. Ainda, para Benjamin a "aura" da obra de arte é aquilo que caracteriza o valor de culto de um objeto autêntico e único, tendo suas origens no caráter ritualístico da imagem, de tradição religiosa, assimilado também pela arte laica, resumindo a sensação daquilo que remete a imagem a algo indescritível. Assim, de acordo com o pensador berlinense, a fotografia e o cinema - esferas diferentes de percepção da obra de arte - apresentam potencial de supressão do rito e, consequentemente, da aura, uma vez que em ambas as formas não seriam perceptíveis a presença do "aqui e agora". Também, importa assinalar que a acepção de Benjamin contempla o caráter histórico, que o conceito de aura abarca, inclusive ligado àquilo que encerra o estrito sentido da tradição, conforme se pode notar pelas palavras de Benjamin ao afirmar que "a unicidade da obra é idêntica à sua inserção na continuidade a que chamamos tradição", uma vez que, consequentemente, "é no culto que a obra de arte aparece inserida no complexo da tradição" (BENJAMIN, 2012, 15). Ainda, segundo o filósofo:

A técnica da reprodução, assim podemos formular, separa aquilo que foi reproduzido e o âmbito da tradição. Ao multiplicar a reprodução, ela substitui a existência única por uma existência serial. $E$, na medida em que a reprodução permite que o receptor tenha acesso à obra em qualquer circunstância, ela a atualiza. Esses dois processos provocam um forte abalo na tradição (BENJAMIN, 2012, 13).

A definição de aura - insinuada primeiramente pelo professor da Bauhaus Lázló Doutora pela UFMG, com pesquisa em Estética e Filosofia da Arte e UERJ, com pesquisa em Ética e Filosofia Política. Brasileira, residente no Rio de Janeiro. E-mail: cinetoscopio@yahoo.com.br 
Moholy-Nagy ${ }^{1}$ - é utilizada por Benjamin pela primeira vez em seu ensaio Pequena história da fotografia, de 1931, elaborada da seguinte maneira: "Em suma, o que é aura? Uma figura singular composta de elementos espaciais e temporais, aparição única de uma coisa distante, por mais próxima que ela esteja" (BENJAMIN, 1985, 101). Nesse texto Benjamin aponta para um modo específico de percepção e recepção da imagem, que segundo o autor já se encontrava em declínio. No entanto, tal abordagem aparece bem mais desenvolvida em $A$ obra de arte na era de sua reprodutibilidade técnica, na qual o autor, tendo retrabalhado o assunto diversas vezes e satisfeito com o resultado teórico alcançado, compartilha suas primeiras impressões com a amigaconfidente Gretel Adorno, em carta datada de 09 de outubro de 1935: "Nestas últimas semanas, identifiquei o caráter estrutural oculto na arte atual, na situação atual da arte, que permite reconhecer o que é decisivo para nós, precisamente no que só agora ganha posição no 'destino' da arte no século XX” (GRETEL \& BENJAMIN, 2011, 265). Ainda, em sua $A$ obra de arte, Benjamin revela que as técnicas de reprodução atingiram um nível tal que poderão impor-se, elas próprias, como formas originais de arte.

O que parece determinante para Benjamin é que com a inserção da técnica mecânica de reprodução artística torna-se possível criar novas possibilidades de percepção da realidade, ou até mesmo outros modos de se construí-la. Por outro lado, o autor berlinense identifica que a reprodução de obras leva a uma desintegração, uma atrofia da aura, tendo em vista que se podem produzir cópias em qualquer momento, sem critérios. O pensador também admite a existência da aura autêntica, por exemplo, nas primeiras fotografias, no período que antecede sua industrialização, mas reconhece que esse momento é substituído por uma massificação correspondente ao declínio qualitativo da imagem.

As exposições universais idealizam o valor de troca das mercadorias. Criam um quadro no qual o seu valor de uso passa para o segundo plano. Inauguram uma fantasmagoria a que o homem se entrega para divertir-se. A indústria de entretenimento facilita isso elevando-o ao nível da mercadoria. Ele se

\footnotetext{
1 Escultor, fotógrafo, pintor e artista gráfico húngaro, Moholy-Nagy em seu artigo "Fotograma", de 1926, referindo-se ao estadunidense e também fotógrafo Man Ray afirma que sua obra consistia em tornar misteriosa uma visão cotidiana, ou seja, "criar uma aura para o cotidiano habitual".

Doutora pela UFMG, com pesquisa em Estética e Filosofia da Arte e UERJ, com pesquisa em Ética e Filosofia Política. Brasileira, residente no Rio de Janeiro. E-mail: cinetoscopio@yahoo.com.br
} 
abandona às suas manipulações ao desfrutar a sua própria alienação e a dos outros [...] As exposições universais constroem o universo das mercadorias (BENJAMIN, 2009, 44).

Conforme Benjamin, a fotografia e o cinema - formas diferentes de percepção da obra de arte - apresentam potencial de supressão do rito e, consequentemente, da aura, significando dizer que o "valor de culto" é substituído pelo "valor de exposição":

Com a fotografia, o valor de culto começa a recuar, em todas as frentes, diante do valor de exposição. Mas, o valor de culto não se entrega sem oferecer resistência. Sua última trincheira é o rosto humano. Não é por acaso que o retrato era o principal tema das primeiras fotografias. O refúgio derradeiro do valor de culto foi o culto da saudade, consagrada aos amores ausentes ou defuntos. A aura acena pela última vez na expressão fugaz de um rosto, nas antigas fotos (BENJAMIN, 1969, 26).

Ainda, sobre a questão do estímulo ótico que algumas fotografias provocavam, Benjamin afirma:

A técnica mais exata pode dar às suas criações um valor mágico que um quadro nunca terá para nós. Apesar de toda a perícia do fotógrafo e de tudo o que existe de planejado em seu comportamento, o observador sente a necessidade irresistível de procurar nessa imagem a pequena centelha do acaso, do aqui e agora, com a qual a realidade chamuscou a imagem, de procurar o lugar imperceptível em que o futuro se aninha ainda hoje em minutos únicos, há muito extintos, e com toda a eloquência que podemos descobri-lo olhando para trás (BENJAMIN, 1985, 94).

O pensador observa também que "a natureza que fala à câmara não é a mesma que fala ao olhar; é outra, especialmente porque substitui a um espaço trabalhado conscientemente pelo homem, um espaço que ele percorre inconscientemente". $\mathrm{E}$, refletindo sobre $o$ assunto, aclara que:

Só a fotografia revela esse inconsciente ótico, como só a psicanálise revela o inconsciente pulsional. Características estruturais, tecidos celulares, com os quais operam a técnica e a medicina, tudo isso tem mais afinidades originais com a câmara que a paisagem impregnada de estados afetivos, ou o retrato que exprime a alma do seu modelo (BENJAMIN, 1985, 94).

\section{VI}

Influenciado, sobretudo, pelos trabalhos de teóricos interessados em pesquisa da história cultural, Benjamin não foi o único autor a abordar o como e o quanto os meios técnicos vinham determinando a arte e a cultura². Mas, decisivamente, foi um

2 Ernst Bloch, em seu livro Herança de nossa época, irá se reportar à questão dos procedimentos técnicos definindo-os como forma de "mediação abrupta", referindo-se não somente à obra de arte ou Doutora pela UFMG, com pesquisa em Estética e Filosofia da Arte e UERJ, com pesquisa em Ética e Filosofia Política. Brasileira, residente no Rio de Janeiro. E-mail: cinetoscopio@yahoo.com.br 
grande entusiasta do tema, focando seu olhar nas mudanças que as imagens fabricadas tecnicamente provocavam na percepção e na arte, direcionando seu interesse para as novas formas de experiência estética na Modernidade mediada pela tecnologia, abrindo novas possibilidades de reflexão sobre 0 assunto. Consequentemente, com o intuito de analisar os fenômenos tecnológicos no mundo moderno e contemporâneo, diferentes teóricos, ontem e hoje, se referem à questão da imagem técnica, sob uma perspectiva filosófica, a fim de apresentar conceitos estéticos que possibilitem refletir sobre o advento dos procedimentos industriais nas artes. Como exemplos mais destacados, Moholy-Nagy se refere ao "reflexo da luz" como sendo aquilo que dá sentido à fotografia, enquanto "escritura da luz", em seu ensaio Pintura, fotografia, cine (MOHOLY-NAGY, 2005, passim) e Kracauer, que exprime tal ideia com a denominação de "imagens do pensamento", em seu $O$ ornamento da massa (KRACAUER, 2009, passim). Ainda, Barthes, que utiliza a noção de "escritura do visível", em sua A câmara clara: nota sobre a fotografia (BARTHES, 1984, passim) e em seu O Óbvio e o obtuso: ensaios sobre a fotografia, cinema, pintura, teatro e música, (BARTHES, 1990, passim), assim como Flusser, ao utilizar o próprio conceito de "imagem técnica" (imagem produzida por aparelho), em sua Filosofia da caixa preta: ensaios para uma futura filosofia da fotografia (FLUSSER, 1985, passim), entre outros.

Apesar da suposta neutralidade conceitual atribuída ao aparato tecnológico, suscitada, aliás, pelas imperativas necessidades determinadas pelas relações de troca, a ideologização da sociedade, através da difusão de conteúdos produzidos para atualizados meios tecnológicos de comunicação via dispositivos midiáticos, tem aprofundado ainda mais o processo de criação de realidades aparentes que, virtualmente mais atraentes e sedutoras porquanto inventadas nos moldes da

\footnotetext{
à forma artística, mas, sobretudo à própria realidade histórica. $E$, da mesma forma, em sua obra $O$ princípio esperança, o filósofo marxista alemão irá afirmar que "Em seu posto cada vez mais avançado, mas também cada vez mais solitário, a técnica carece da conexão com o antigo mundo crescido, do qual o capitalismo se deslocou, assim como da conexão com algo da natureza que seja favorável à própria técnica, ao qual o capitalismo abstrato nunca consegue encontrar um possível acesso" (BLOCH, 2006, 246).
}

Doutora pela UFMG, com pesquisa em Estética e Filosofia da Arte e UERJ, com pesquisa em Ética e Filosofia Política. Brasileira, residente no Rio de Janeiro. E-mail: cinetoscopio@yahoo.com.br 
sensibilidade comum, tem proporcionado novas formas de escape e dissimulação das relações entre cultura e sociedade. Além das inerentes questões estéticas envolvidas, decerto a discussão suscita uma abordagem de dimensão ética, sobretudo no que se refere ao campo da cultura e educação, pois diz respeito ao refinado processo de violência que resulta no embrutecimento da sensibilidade por meio da ausência de reflexão crítica numa sociedade condenada pelos efeitos da máxima exposição e repetição da imagem técnica. Segue-se a isto, o fato de que os recursos dos media atuais determinam novas formas de interação entre cultura e indústria por meio de dispositivos tecnológicos que, armazenando e possibilitando a manipulação de conteúdos virtuais, determinam perspectivas reatualizadas de usos da cultura.

Evidentemente, a garantia de ingresso equitativo no mundo dos recursos tecnológicos atualizados nos países de economias hegemônicas, da mesma forma que representa uma demanda das sociedades complexas atuais necessita também ser dimensionada em um sentido mais amplo e, portanto, eminentemente crítico, na medida em que transformam as relações entre indivíduo e sociedade, demandando também um redimensionamento dos modelos hegemônicos vigentes de comunicação de massa. Em outras palavras, significa dizer sobre a necessidade de realizar uma crítica à tecnologia enquanto crítica de seu uso absolutamente econômico e não social por parte dos conglomerados que detém tanto os meios de produção de aparatos tecnológicos comunicacionais atualizados quanto os meios de produção da informação, podendo-se identificar tal mecanismo com um também complexo sistema de controle sociocultural engendrado por grandes agências de interesses políticos e incrementado pela totalidade dos media disponíveis.

Para além do evidente sentido de positividade que a reprodução técnica encerra, não é fora de propósito pensar que tais modelos de produção pouco atendem às questões atinentes ao potencial da arte, desvirtuando, por exemplo, o seu próprio sentido de unicidade (o hic et nunc benjaminiano), caracterizando-a como mero produto tecnológico sobrevalorizado em termos quantitativos para uma sociedade igualmente quantificada. Tal discussão tem no âmbito da arte um campo privilegiado de análise crítica das relações que se estabelecem entre história e filosofia, bem como 
a necessidade de reflexão sobre a hegemonia cultural, levando em conta considerações sobre as tecnologias atualizadas, enquanto formas de transmissão da cultura. Como pontuado por Benjamin desde o início do século XX, sobretudo com o advento do movimento futurista, tal esfera hegemônica já se configurava de forma conservadora e burocrática, com dimensão notadamente pragmática.

Não se pode, portanto, olvidar que na obra de Benjamin encontram-se os rastros que possibilitam elucidar o quanto a disseminação acrítica de uso indiscriminado da tecnologia na era industrial, nas suas diferentes formas de produção, reprodução e difusão, modificam, inclusive, as noções de espacialidade e temporalidade, elucidação essa possibilitada por uma reflexão sob outro prisma: o de uma memória histórica sobre a qual se baseia a identidade, em oposição à dicotomia entre os conceitos de tradição e Modernidade.

\section{VII}

Muito embora originada em um mundo ainda não dominado pela estetização da realidade, pode-se dizer que a análise benjaminiana sobre "a obra de arte na era da reprodutibilidade técnica" constitui ainda hoje uma vigorosa contribuição para o entendimento das questões atinentes aos avançados processos em curso de industrialização da subjetividade dos indivíduos, embasados na tecnologização virtual da realidade. É nesta ótica que sob um viés crítico aos processos industriais nas sociedades complexas atribui-se ao véu tecnológico (technologischer Schleier) o aspecto de objetivação também da arte na medida em que arbitrariamente possibilitam tanto a produção de conteúdos formatados quanto a manipulação objetivada daquilo que é produzido com finalidades absolutamente mercantis.

Certo é que sob relações determinantemente institucionalizadas e condições de vida definidas pelos avanços tecnológicos, a totalidade das relações sociais que possibilita as relações de existência entre os indivíduos não é mais dada sob a perspectiva da experiência, decorrendo daí o rompimento potencial entre estes e a realidade histórica, transformando a experiência vivida em experiência potencial. $\mathrm{O}$ que resulta disto pode ser entendido como uma contradição entre as visíveis condições 
de existência social e modelos hegemônicos de experiências simuladas em termos idealizados, tornando os indivíduos em espécies de satisfeitos simulacros de si mesmos. No sentido do distanciamento entre tais esferas diferenciadas, delineia-se aquilo que a dialética tradicional hegeliana determina como essência e aparência (Wesen und Schein), podendo ser aqui interpretada enquanto experiência real e experiência virtual. Sob este enfoque, no que respeita à arte a experiência do indivíduo termina também por se tornar absoluta em nome de uma aparente experiência de natureza coletiva, de segunda categoria, que limita o aspecto essencial de sua vida subjetiva, inviabilizando qualquer possibilidade relacional de sentido particular, significando dizer, em outras palavras, que resumida em termos de singularidade subjetiva, a experiência estética, diferentemente da experiência social, pressupõe a supremacia do individual sobre o coletivo e não o contrário. É essa experiência de ordem singular, caracterizada pela não identidade com a totalidade do sistema tecnológico hegemônico, que parece não ser mais possível em uma sociedade unânime, viável somente em uma realidade de primeira categoria que remete à essência em si mesmo dialética da experiência vivida, sequer pensada em termos conceituais e enquanto uma determinação da maior parte dos indivíduos.

Igual tensão entre particular e universal é o que irá determinar também a própria arte, definindo, enquanto contradição, a sua separação do mundo real, ou seja, a oposição do princípio de realidade que faz da arte a representação perfeita do mundo real imperfeito, sendo esse o seu duplo caráter. Em outras palavras, a arte, enquanto algo não existente no plano do real se serve de elementos da realidade para determinar a sua existência. E é justamente porquanto algo inexistente no plano do real que só se pode falar em arte tecnológica como um conceito operacional e em um contexto no qual a arte se encontra em termos absolutos objetivada como produto, resultando daí o apego generalizado e incorporado de forma incondicional tanto pelo senso comum quanto por setores atualizados da crítica da arte. Diferentemente do que supõe o pensamento positivista, pode-se identificar como tal na vida dos indivíduos uma já segunda natureza adaptada à totalidade do sistema sócio-político-cultural industrial e midiático hegemônico, situando tal fenômeno no âmbito de uma relação de 
identidade entre sujeito e objeto.

A esse propósito, conforme referido anteriormente, Lukács, em sua História e consciência de classe, descreve o quanto a própria realidade aparece como uma espécie de procedimento técnico, dimensionada principalmente em momentos de crise. Como consequência, pode-se dizer também sobre o rompimento entre a experiência vivida e a dimensão do sistema econômico mundial enquanto totalidade hegemônica, ou, em última instância, entre existência individual e história em termos sincrônicos, determinando crises de natureza sócio-política-cultural e econômicas modelares como as que, há muito, insistimos em vivenciar. Decorre daí uma ruptura radical entre o indivíduo e sua realidade histórica, sendo tal ruptura aquilo que transforma a relação entre a experiência vivida e o processo histórico. Sob um contexto hegemônico tais esferas enquanto formas tradicionais não são mais capazes de formular algo que vá além de harmoniosas e apaziguadoras formas de experiências sociais constituídas em termos virtuais, aparentes e, portanto, contrárias a perspectivas essenciais dimensionadas no sentido contraditório do real. Da mesma forma, uma vez que os recursos tecnológicos avançados, enquanto algo descontínuo está longe de ser uma resposta às questões estéticas formuladas pelos artistas como resposta à realidade histórica da arte, tais recursos se apresentam ainda como sintoma de uma realidade socioeconômica e cultural que embora atual, é da mesma forma herança de um tempo o qual ainda aguarda uma interpretação de seu significado.

\section{Conclusão}

As tendências hegemônicas e uso desigual dos chamados novos media servem de base para ilustrar a dimensão dos aparatos tecnológicos no processo de mudanças das relações que se estabelecem entre arte e sociedade, delineando o seu significado no âmbito de uma análise de sentido materialista. Tal análise, por suposto, não diz respeito ao esgotamento das possibilidades de emancipação da arte, objetivando, ao contrário, demonstrar que o que pode caracterizar tal emancipação nada mais é que o esforço de sempre relacionar a arte enquanto crítica ao mundo dos processos 
industriais e da ação econômica e política. Compreende-se, pois, que a relação de tensão entre arte e sociedade constitui o lócus privilegiado de análise dos vínculos intrínsecos entre aparatos tecnológicos e produtos de mercado regidos pela primazia dos meios em detrimento dos fins. É sob tal ideia que a arte se insere de forma singular enquanto esfera privilegiada de conhecimento e apreensão do real, modelada em termos de um pensar não conceitual que não por outra razão se encontra apto para justamente se contrapor às formas reais de apreensão do que é subjetivo. E como consequência, pode-se pensar sobre a possibilidade tanto da arte quanto da cultura de se constituir ainda como mediadoras das relações entre a subjetividade e a objetividade dos meios, ou por assim dizer, entre o indivíduo e a hegemonia do sistema industrial econômico, em oposição ao exemplo da sentença hegeliana que, em outras palavras, afirma não ser mais a arte a forma superior sob a qual a verdade se faz existente.

\section{Referência bibliográfica}

ADORNO, T. \& HORKHEIMER, M. Dialética do esclarecimento. Rio de Janeiro: Zahar, 1985.

ADORNO, G. \& BENJAMIN, W. Correspondência: 1930-1940. Buenos Aires: Eterna Cadencia, 2011.

BENJAMIN, W. A obra de arte na era de sua reprodutibilidade técnica. In: Benjamin e a obra de arte - técnica, imagem, percepção. Rio de Janeiro: Contraponto, 2012. / Rio de Janeiro: Zahar, 1969.

Baudelaire e a modernidade. Belo Horizonte: Autentica: 2015.

Charles Baudelaire: um lírico no auge do capitalismo. Obras escolhidas, volume III. São Paulo: Brasiliense, 2000.

Magia e técnica, arte e política: ensaios sobre literatura e história da cultura. Obras escolhidas, volume I. São Paulo: Brasiliense, 1985. Origem do drama barroco alemão. São Paulo: Brasiliense, 1984. Passagens. Belo Horizonte: UFMG/São Paulo: Imprensa Oficial, 2009. BAUDELAIRE, C. Sobre a Modernidade. Rio de Janeiro: Paz e Terra, 1996. BARTHES, R. A câmara clara: nota sobre a fotografia. Rio de Janeiro: Nova Fronteira, 1984.

O óbvio e o obtuso: ensaios sobre fotografia, cinema, pintura, teatro e música. Rio de Janeiro: Nova Fronteira, 1990.

BERGSON, H. Matéria e memória. São Paulo: Martins Fontes, 1999.

BLOCH, E. O princípio esperança. Vol. II. Rio de Janeiro: Editora UERJ/Contraponto, 2006.

Doutora pela UFMG, com pesquisa em Estética e Filosofia da Arte e UERJ, com pesquisa em Ética e Filosofia Política. Brasileira, residente no Rio de Janeiro. E-mail: cinetoscopio@yahoo.com.br 
BUCK-MORS, S. Estética e anestética: uma reconsideração de $A$ obra de arte de Walter Benjamin. In: Benjamin e a obra de arte: técnica, imagem, percepção. Rio de Janeiro, Contraponto, 2012.

COLLARES, G. Imagem digital e manipulação: a contribuição de Walter Benjamin para a era da reprodutibilidade de verossemelhanças. In: Walter Benjamin: imagens. Rio de Janeiro: Mauad X, 2008.

FLUSSER, V. Filosofia da caixa preta: ensaios para uma futura filosofia da fotografia. São Paulo: Hucitec, 1985.

FREUD, S. Lembranças encobridoras. Obras completas, vol. 3. Rio de Janeiro: Imago, 1996.

KONDER, L. Walter Benjamin - o marxismo da melancolia. Rio de Janeiro: Campus, 1988.

KRACAUER, S. O ornamento da massa: ensaios. São Paulo: Cosac Naify, 2009.

LUKÁCS, G. História e consciência de classe: estudos sobre a dialética marxista. São Paulo: Martins Fontes, 2003.

MARX, K. Manuscritos econômico-filosóficos. São Paulo: Boitempo, 2004.

MARX, K./ENGELS, F. Manifesto comunista. São Paulo: Boitempo Editorial, 1998.

MOHOLY-NAGY, L. Fotogramm. Kassel: Weber \& Weidmeyer, 1991. Pintura, fotografía, cine. Barcelona, Gustavo Gili, 2005.

SANTAYANA, G. The life of reason - or the phases of human progress. New York: Charles Scribner's Sons, 1920. 